\title{
Image and Space: Qing Yang "Eight Sights" Culture during the Ming and Qing Dynasties
}

\author{
Xinghe Lei
}

\begin{abstract}
Eight sights", in Qing yang city during the Ming and Qing Dynasties, is a typical representative of the urban landscape in regional society, "eight sights" in Qing yang city and other "eight sights" in each country of Qing yang are presented to us a good picture and rich historical and cultural relics, showing the profound meaning of magical calculating culture, meanwhile constructing the urban spatial structure with artistic style. "Eight sights" embodies the marvelous combination of cultural landscape and the natural one, the symbol of magical calculation and art image; it also embodies the implication of beauty and the miracle space structure, at the same time the beauty of the picture mixed with legends of mystery and real sights.
\end{abstract}

\section{Index Terms-Qing yang, eight sights image.}

\section{INTRODUCTION}

The generalization of "eight sights" contains numerous cultural connotations, many places of historic interest and landscape in our country by the ancients summed up four word format language, each selected eight representative landscape will be referred to as the "eight sights". During the yuan Ming and qing dynasties, the "eight scenes" were not necessarily eight scenes or "eight scenic spots". There were ten scenic spots, twelve scenic spots and so on. This was not only a summary of the scenic spots, but also a manifestation of the cultural culture.

In traditional Chinese culture, the Numbers are closely related to "zhouyi" and often represent mysterious meanings. "Nine" stands for honor, so there is the "95th". The "eight" and "hair" are a lucky number, representing auspiciousness and beauty, which are deliberately used in many aspects. After song dynasty, the song dynasty was especially prominent, with the general situation of song dynasty: "tang and song eight", "eight immortals", "yangzhou eight monster", "eight diagrams" and so on. The Arabic numeral 8 is very similar to the symbol of infinity as long as it rotates at 90 degrees. "Eightscape" is not only the scenery, but also the culture and the beautiful image.

In the ancient geographical orientation, the orientation of the east, south, west and north was first, and then the orientation of northeast, southwest, southeast and northwest were produced [1]. Some scholars think that "all the eight azimuth represents the geographical space, and developed into endless culture idea, gossip, gossip is a symbol of nature of the universe's original state, dry days, kun symbol, seismic ray, xun symbol wind, symbol of water, the symbol of fire, gen symbol mountain, the symbol, heaven and earth FKB water world the eight kinds of natural things

Manuscript received January 19, 2018; revised April 11, 2018.

Xinghe Lei is with Longdong University Institute of History and Geography, China (e-mail: leixinghe@126.com). constitute the foundation of the universe". [2]

Thus it can be seen that in the accounts of traditional Chinese "geography" and "local Chronicles", the expressions of "four to eight" have a long history. This "four to", "eight to" space expression, is the purpose very clear to tell the reader "area" and "space" and "spatial pattern". Therefore, the reason why "eight" is to take the number " 8 " is the cultural image and the space orientation.

\section{THE "GEOGRAPHICAL VICTORY" OF QINGYANG GOVERNMENT}

Qingyang fucheng city with a long history, is the earliest and most complete in the history data about qingyang fucheng construction record is jiajing years Fu Xueli in qingyang government record volume 2 records: "qingyang house because of the original mound trend, its shaped like a chicken, so yue phoenix... (in the early 1466 years), zhu yingjian was involved in the search for bad water. The vice made cao hongfu build. In the twenty-seventh year of jiajing, he joined the government of wang shanning, which has about six or seven li's. The first three days of next July will be flooded. In the spring of thirty-five years, the governor of the state of zhifu rebuilt it. According to the danger of the mountain and the river, the solid of the city soup pond, the party is a danger to the cloud. North guan city, zhou qi xu, the city opened three doors, the north yue, the north, the east, xuanhua, the west yue gate, the construction of three stacks of buildings, the tour. [3] since then, qingyang fucheng has been repeatedly damaged by the war and natural disasters, and has been refurbished many times. At the end of the Ming dynasty, most of the walls and gates were destroyed.

In the fifteenth year of the reign of emperor shunzhi (1658), he was divided into two parts: zhang yuanzhi of the hexi river and Yang xinfeng, the governor of qingyang, to rebuild the city, building four towers, eight enemy buildings, and 24 hare-houses, and 79 women's parapets. Qianlong was restored in early years. Guangxu 15 years (1889) zhifu hu litudor repair. Xuantong repaired the parapet for three years, and 34 police houses. The republic of China has been fixed for a decade. In the 16th year of the republic of China, there were 64 police houses, brick walls and brick walls. [4] qingyang fucheng has been repeatedly destroyed and restored, but it has been kept in the pattern of jiajing period.

"The construction of ancient Chinese cities is very elegant, and it usually depends on water. The best place to build the city is to give the place to the sun. If there is a mountain outside the city that is built. To lean on mountain city, and the mountain is relatively far away from the city, to build the city in the east and south of the mountain, that mountain xiangyang, in the north of the city or in the northwest mountain for good, southeast direction develops, the city was 
built on such relief and such a great location." [5] qingyang fucheng is built on top of kaofu. It is surrounded by two water surrounded by mountains. Again to cut mountain city, TuTai side of edge, is naturally formed steep, soil is set on the wall, so as to appear very high walls, according to the current remaining measuring qingyang fucheng wall top 40 meters, the lowest in 20 meters. Two water clamps, the bottom is a stone base. The core of China is hard to defend. [6] historical records: "qingyang fu (anhua county) city is high, the pool is as deep as a spring. The ground picks up hu qiang, the original xi dangerous resistance. Two water confluence, group peak ring, dragon disc fengzhu, golden city soup pond. The front band suiyan, the screen. The city is chipped away. Take the river for the pool." [3] C.D. Bruce, a British examiner in the late qing dynasty, also praised the city as a natural defense stronghold, comparable to any ancient castle that can still be seen across Europe. [7] you can see the Great Wall of qingyang fucheng.

There are many buildings in qingyang fucheng, mainly along the layout of six crosses of fifth street. According to predecessors "qingyang government record", and "qingyang county annals" in the Ming and qing dynasties qingyang year except qingyang government department and anhua.we will act department MingXian cases of chenghua eleven years (1475 years) to expand on the south slope of the northern song dynasty period in honor of fan zhongyan defended border Fan Gong shrine, and add the 2nd anja, called the "fan han temple". In the years of mingzhengde, the goose pond was rebuilt and dredged. Goose pool hole, once one of the eight scenes of qingyang, namely "goose pond spring water". According to fu xueli's "qingyang fu zhi", the goose pond affair, do not know the beginning of he dai. In the tang dynasty, the county engaged in the dredging and recording of li kexin. In the song and qing dynasty, [3] the goose pool hole should be built earlier than the end of tang dynasty. The long history of goose pool cave also confirmed the ancient city of qingyang city from the side.

In addition, qingyang fu city also has numerous temples, pavilions, and palace views. Except now shines temple and CiYun temple, temple has been, lu temple, the wind, Huang temple, west temple GuanMiao, yuquan temple, guandi temple, eight wax temple, Buddha temple, the xuan emperor temple, too white temple, fu qingyang temple. Shanqing temple, ciyun temple, and kyung kwan temple. The pavilion has a town view building, a massive tower, a rising official building, a bell tower, a small gate, and a meeting of jia people pavilion. The brick tower is a brick tower, a brick tower, a brick tower, a brick pagoda. The palace, the view namely the palace, the good view. [8]

\section{GEOGRAPHICAL VICTORY IN QINGYANG "EIGHT SCENES"}

The site selection of ancient Chinese cities is very exquisite for "mountain chuan", which not only meets the need for natural functions, but also pursues the feng shui of the integration of mountains and cities. The "geomancy" thought of the "divination" site of jiancheng has been budding since the "zhou gong's work" in the western zhou dynasty. General use later, after a gradual development lag formed the ideal model of feng shui, namely: the "dragon vein, four elephants (blue dragon, white tiger, rosefinch, black), case on the mountain, the mountain, shuikou, drains" [9] and so on, eventually forming the ideal "meridians". In the evolution of culture, the geomantic pattern has the superstition, but undoubtedly the selection of the environment and the construction of the landscape constitute the unique landscape image and artistic aesthetics of the landscape city.

In the "scenery", "qingyang fu zhi" has such a record: "xiongxi qifeng, zhaohua yu, the miao miao, the old park, the generation of the family. All of them are in the name of the scene, the non - fund to enjoy the view. The land in the north is not beautiful, although there is no jincheng flower county, the west lake of east shu, but the temple, the temple of the temple, there are also. The gentleman of the pleasure, the time or the view of the scene, the sense of the ancient and the talented, the book of the appropriate record. It is a good idea to make the first time, to expand and bring up the quantity of salty hennessy, and to help the clouds. [3]

Qingyang fucheng "eight sights" is actually a "ten sights", namely: "Zhou Zu qin ling", "new Kong Sheng palace", "ancient DiGong temple", "Fan Gong curtilage", "goose water", "dragon qiushui night moon", "igawa fine snow", "Peng Yuan WanZhao", "south of the city church" and "shine out clock" [3]. Qingyang fucheng "eight sceneries" human landscape and the natural landscape amount is quite, "the geographic victory" and the city integration, constitute the perfect image of the city of the mountains and rivers.

The "eight scenes" in ning zhou is the proof of wang zhong's eight views: "the ancient characters of liang gong are flawless, the qin is noisy and the ravens are noisy, and he has a smooth and purple stone. The spring dawn of Kowloon is very much admired, the three water confluence is very much, the most love of jinquan cliff side of the bank, guan ting the night hang tianya." [3] the "eight scenes" in ning state embody the perfect integration of humanity and nature. The two places of "liang gong" and "qin chu" are the cultural landscape, and "guan ting night" is a combination of humanity and nature. "Wuchuan purple inkstone", "mountain sunset", "chunxiao in Kowloon", "sanshui confluence" and "jinsha spring" [3] show the beauty of natural mountains and rivers.

The county seat of the ring county is located on the edge of the huanjiang river. The river flows from north to south through the city. Ring county "eight sights" in addition to the unique natural environment, and is closely related to the historical heritage, the "eight sights" is as follows: "LingWu ancient Taiwan", "Xiao Guan communist-held", "Ma Lan GongCui", purpose among serious streams garden ", "pearl river spring pu", "ocean toward the rain", "table mountain snow ji", "screw YanQing organ" [3]. "Xiao guan ancient road" is listed as one of the "eight sceneries" in the county, and it is the military geographical position that highlights the historical "xiao guan". "Qingyang fu zhi" has such a record to xiao guan's hometown, "in the county north thirty li, namely ancient xiao guan also. The frontier hua yi, the prohibition of the heretic, the ancients equipment side circle, this is the important ground. As the land of the land, the land of horan, which is owned by xiao guan, has not been in place since ancient times. The gentleman of the earth, can be 
induced to feel very much." [3] it is clear that xiao guan is important in the ancient military geography.

Qingyang "eight sights" listed in the "celebration of fine snow", the "eight sights" in the county included in the "table mountain snow ji", the main reason is qingyang is located in the northwest, the winter cold, snow after hemorrhage forever, is clear because it is so bright, so the region landform scenery picturesque after heavy snow in the winter. "In qingyang qingyang government record table fine snow" has this description: "in FuZhi, four mountains and obstacles, but the city open and flat, 歭 four broad, if looking to have a platform, so the name. After the winter snow fog, yao qiong product, fragrant and picturesque, it has the flavor of the pride and light. Once upon a time, the so-called "yichuan, yichuan, yichuan" was almost insufficient to describe its fine art. And the wonders of the world. The situation is presented to zhaoxia, and there are people who are out of view. Wu shi-ying's poem cloud: teng six shi gong lai shear plant, chaoyang to fly out of the white cloud heap, the orange step jade to build a thousand barrier, the bead tree qi flower to open overnight. But the envy of the sanyon's wear, why not to the cruises back, the first three white who show rui, should listen to the music platform." [3] "fang shan ji xue" in huan county is also recorded: "in the southwest of the county, fang fang is like Taiwan, hence the name fang shan. Xue ji yu, the sun blanching, there is a silver case, a distant view of the view, the foot of the eyes. As for the tree maolin, perpendicular jade zi zhu, jingjia side. The man has the chant, to remember the man." [3] such a landscape is not only a rare natural wonder in a special geographical environment and a special time, but also a view of the city.

The "eight views" of heshui county are located on the outskirts of the city, and all of them are natural scenery. The city relies on the "geographical victory" of nature to form a vision of the outskirts of the city: [3]

Nanshan mianshan: namely the south mountain of the county, with the screen of the barrier, and the flowers and trees. The time value yangchun high summer, red bibi dispute. Fang is gorgeous, like the beauty of the brocade capture, the ancient yue "the tapestry".

Pen lingyun: in a county in the south, the mountain stands straight shrugged, towering $\mathrm{Zu}$ 嵂, if have pen rack, people called pen peak. If the sky is high, the sky is high.

Xishan evening photo: in the west of the county, the mountain is rugged and magnificent, the forest is flourishing, also one side wei guan also. On duty, the birds are in the sky, and the birds are still in the sky.

Feng chuan yun: in the east of the county, the cloud of fang yanyu: clear and clear, the gull is swimming, also a place of victory. View of this, right here have taken to the ancients also old enough, ReFu kuang Dong overlook, see the smoke layer, changes in the float in the sky, thousands of state, a sprinkle however have asked qing $\mathrm{xu}$, get rid of, the hubbub of the boring, not here, witty, Ann can zai is moving to?

Mei shore dongxiang: in the county east 30 li, namely yu meichuan, the source of the meridian mountain, east into the Chinese pool, the water name meichuan. Stolen or at the time it was a river and so on. Today may not save, but more he wood, the value of winter snow fall, far tree, the branches of the trees, like the sea's vomit. What is the best way to make sure that you have the right to be a jade?

Shengquan spring water, in the county south ten steps, namely the holy spring. The cloud of "fang yisheng" : its ancient practice meritorious person zhuo tin, out of the spring, can be more sick, the morning prayer also should, because of the name "sacred spring". Every spring fusion, the flow clarifies, the human body takes the bath body eye-catching, and carries the wine with the dish, pan-high, the singing competition, if really interesting. The reward is the salt of the mountain.

Baozhu xiushu: in the county of nandulibao spring temple. Spring is like a pearl, the name of the treasure. Water accumulation pool, training and gullet turbulence, the morning sun screen, float gold, if the cape, the brocade spray bead, will be a victory. The sanghan, with its huts and huts, was waiting for the reward, but now it is invalid.

Stone rain: in the west of the county, there are cliff rocks, every rain of rain, give first wetting, if the corner of the sun, although the hyperactive heat of the sun, run as well, the city is known as the rain. As it is, it is also known as the qi.

Heshui "eight sights" completely focused on the mountains and rivers, the winding mountain scenery, the city in the mountains surrounded by standing still, inner cities without "eight sights" heshui is typical of the "eight sights".

The eight scenes in zhenning county are eight scenes, and the "geographical victory" is integrated with the city and blends with each other. In this county, the king was given 15 views. It's a chant. Specific for: [3] jean mountain ancient hole, bowang rabbit hole, pengzu mountain heritage, pagoda hill site, bridge mausoleum, qiushui ancient temple, Yang zhou city spirit, fruit old magic's tomb, Wan Shouxiao clock, YueShan night cui, shek mun, cui, longmen natural barrier, the monastery HeChi, double LiuSe river. True ning "eight sights" compared to other "eight sights" qingyang, "jean traces of ancient hole, pengzu mountain hills, bridge mountain tomb" and "fruit old magic's tomb" these four spots are legends, this sight by legend as is really rather prominent feature of "eight sights".

\section{The Urban Structure of Qingyang "Eight Scenes"}

Qingyang mansion in the administrative position and geographic centers under the background of humanity and nature, qingyang fucheng adjust measures to local conditions, conforms to the guanzhong urban construction thought, "rules, road in the musquash don't don't of the criterion". Along the two rivers of the river and the soft river, the city gate and the city wall are arranged in order to reflect the perfect combination of landscape and landscape. In qingyang "eight sights" can clearly highlight in qingyang characteristic of fucheng axis "mountains and rivers" is "goose water" and "Peng Yuan WanZhao", a north, south, highlight the "eight sights" bearing structure and spatial characteristics.

The goose pond spring water, in the north. "If the pool is the source of the flow, the east stream will be built, and the building of the castle will be sufficient to be widely read. In the middle of the city block, enough to apply to the group. To value ChunHeJingMing, ripple transparently clear and limpid, tackled kam cloth embroidery, quotation from irrigation, almost enough to bath with bath of DE yi heart, 
waiting for the cabinet, two sichuan blue, four mountain GongCui, group of wood, and wan ou fang, not increase near the xuan interlingual transfer and deng peng gallery, this is the most also. But the pool takes the name of the goose, not knowing what it means, or the name of the bath goose at that time. Pool and four, and alone in the spring, take cover, wipe the superiors Wu Shiying did: two shadow of willow south Beijing, fang pool water garden heavy shen, the ancients had to goose far, spring wat deep vein mutually dragon, moss green tasks in prison yao, cool living Shi Jian spirit dreary and desolate, filled with xu to sit properly, try to spring breeze songs alone." [3]

"Peng yuan late photo, in the south of the state, namely pengyuan waste county, the temple of the ancient temple. The temple has been destroyed, but only the pagoda. The tower of ten, soaring high. Each of them falls, and at dusk, the top of the tower looks like the sun, the bright light, the far and near, the long is the interest. The view of the scene, brother to the "the light of the light, the palm of the heart by the way". The gentleman does not abandon the land. Wu shi-ying's poems: the plain rain of the forest, the autumn and the west wind and the grass, the grass and the deep two rabbits, a bird in the sky. Flute rhea smell belong to the priest, axes 嶕 rhyme tintin to late, smug dressing no fight cut, why feelings a Ming dynasty." [3]

The "mountain axis" of qingyang fucheng is characterized by north and south, and the state of ning is a feature. The two east and west sides of the "eight scenes" are clearly marked by the urban axis. "The night of guan ting, in the east of the state, the three rivers. If there is a stand on the side of the hill, the temple of king wu 'an is built. Every night of the night, moonlight water color, up and down, rippling clear, have the meaning of the world outside. The "got talent" is a kind of person who takes a tour of the city to enjoy the loyalty and loyalty of wu 'an. [3]

"Chunxiao, Kowloon, is one hundred and twenty leagues east of the state. The earth is fertile and can be sown. The state has built a lot of beds in the garden of the garden, the garden of the garden, the garden of the garden, the flowers and the flowers, the giant fruits and vegetables, fighting for a long time. Each of the spring thaw flower hair, ascend to the height of the view, see the red and purple show, the peach li yan, qianshani, is in the jinyi wen, cheng side shengjing also. People are the scholars of the state and the generation of master of letters. [3]

"Hu chuan zi yan, in the state west $30 \mathrm{li}$, namely coral chuan also. The source of anhua county, flow into the ma lian river, the flow of the long, follow the great sichuan name, the east. When there is autumn pool, pray for the drought, not the yingxiu, how to be? Its chuan produces purple and stone, warm and moist luster, can make inkstone, for stationery, also the resort also." [3]

"The tomb of qin, in the west of the state, is the tomb of the prince of the qin dynasty. The stone tablet is the servant, the thorn qin is desolate, the longtou you are the tree, love the huang2. Bury the grass and bury the sheep. No one will be able to tell the difference between the qin season and the death of the flesh. [3]

Ancient city in the process of formation, according to the functional requirements and culture connotation, architectural layout such as palace, temple, market into a certain pattern, to express the most typical landscape city, forming the nods eyeball pen of urban landscape. For example: qingyang prefectural "zhou zu-ling", "the universal faint bell" and "the city south xiaoshi".

"Ling of Zhou Zu, namely the fucheng dongshan, Zhou Zu 密 old burial, also not Gao Fu open and flat, overlooking overlooking, mountains and cities, suddenly the eye. It is a good idea to let the people know that they are not happy. So this is the first cloud. It was awarded to the four Ming dynasty wu shi-ying's poems: in the eighth autumn of the reign of emperor, the grass was thick and the grass was thick. In the spring rain, the gods return to the clouds, and the passers-by should ask, "the yellow soil is still week." [3]

"In the north of the court, in the north of the court, in the north of the court, the tower of the temple of the temple of the king of the king of the temple of the king of the temple of the king of the temple of the king of the temple of the temple of the temple of the temple of the temple of the temple of the temple of the temple What is unique to the faint bell? The word Lin yi wan is a multi-zen forest. It is pure and elegant, enough to cultivate love. In the time of si, the dream of songxuan, the van dian feng qing, is the realization of the vacuum and the beauty of the night. There is a husband of the king. Wu shiyun: the drum temple has been a long time, the only time is to send the jinghui, the wind sheng bihan whale to roar, the people of the quiet of the cranes has returned. The bamboo yard spring outing is weak, maple bridge night resistance. The official is old my side city guest, a few times the home is yong." [3]

"The city of nanguan, in the south of the city, is the building of goods, the trade of merchants. The city is dense and connected. In the morning, the city of shimin will be in the city, and the noise will be loud and loud. The reason for this is also the case. In the case of the connoy of the afternoon, he suffered from the water of his own, and suffered from the changes of his own. The land of the former pyrotechnics has been a lonely place for the moraine. Is it possible to live in the past with the fading of the teeth and the business of the merchants? Wu shi-ying: the landscape of qingzhao, the city of the city, the noise of the city and the smoke, the mountain people if the emblem of the emblem, the wild life is a thin Lillian. It is like to say that the base merchant has a monopoly, a few spring dreams of springfield, the west of the lanqi is like painting, who fu poonhai. [3]

In short, in the city "eight scenes", because the city relies on a certain geographical victory, "eight scenes" can be clearly reflected in the local conditions of the space structure.

\section{SPiritual NeEds in Qingyang "Eight Scenes"}

In ancient China, the overall layout and construction of cities from cities to cities were integrated with the basic functions of the city. The formation of a city should first meet the basic needs of life and economic foundation, then gradually meet people's spiritual and cultural needs in the process of social development.

Professor Li Xiaobo combine cities and mountains and rivers of cultural landscape is divided into three levels, "all of the system -- -- between between people god, and from the life of reproduction worship in the mind of the instinct 
pursuit, and safety requirements, clan society of blood ties, aesthetic feeling happy, the concept of the unity of nature and the universe, five aspects were described in detail." [10]

In the "eight scenes" in qingyang fucheng, the worship and admiration of ancestors, saints and heroes is one of its themes. For example, qingyang government has "kong shengxin gong", "di gong gu temple" and "fan gong old house" three places: "kong shengxin palace, namely the temple courtyard of the temple of fu zhi nan, the remaining of the enemy in the war. The forefathers, who have been in charge of the government, have been constructed and new. It is the palace walls that are all over the place, the cultural relics, the cultural relics, and the tour of the period. It is not only to be able to change the way of chongru, but also to be able to sing and sing. Oh the political rules: reed decay for twenty years, almond altar annihilation grass lush, the five-star wufeng Wen Yun, completion the plugging up see, in the days and static crown race curtain night string recite months pass, welcome when sheng xing culture and education, make lotte LvYan sex." [3]

"The temple of digong, the north dike temple of ningzhou, the back of the cliff, the west ring qingxi, the juniper juniper, the long pine and the Yin, the gong is angry. Therefore, the rioters, the king of mugong, were the most beautiful people in the world. Wu shiyun: the ancestral hall is a thousand times the mountain head, which has been called the sadness of The Times, the green grass yellow flowers and silence, the white cloud water flowing from leisurely. The sincere return of the woman is loyal to the house, the benefit of the benefit of ningmin ze shang, the base son lucky to pursue the old track, the tears in the autumn." [3]

"Fan gong old house, now change to qing reservoir... . The later generations of the duke and the government, or the "jingfan" or the name of the "second fan", also known as "the hall of love", "a fan hall", are all the people who are very good at it. Therefore, we have no doubt that we are not worthy of the name of the house. The gentleman took the name and had no intention of doing so. Wu Shiying did: migrating south song room will do, only empty house posterity, righteousness spirit in China, air force xiong heart tremble, smoke the misfortune mountain, vast and lonely night former nest month tuan tuan, life can only be so, adoring how no." [3]

There are two places in ning state, "liang gong gu memorial" and "qin storage tomb", "liang gonggu monument... The ancient tablet is an article written by fan gongzhong. His essay, on the first day of the tang dynasty, was a great one to read. In the state of the state of the state, after the relocation of the state, the king's party was falsely falsely said, and two thousand people were killed. The duke was able to save and rescue him, and he was in the state of the state, under the memorial of the weeping and the weeping. In the play! Public morality is deeply moving, and if you care more than that, you can learn about it." [3]

"The tomb of qin, in the west of the state, is the tomb of the prince of the qin dynasty. The stone tablet is the servant, the thorn qin is desolate, the longtou you are the tree, love the huang2. Bury the grass and bury the sheep. No one will be able to tell the difference between the qin season and the death of the flesh. [3]

In qingyang "eight sights", many of them embody the spiritual pursuit, qingyang not only abundant natural and human landscape, and numerous historic sites, successive humanities, the ancient, dee renjie, fan zhongyan, Li Mengyang poets such as the teachers of the law in qingyang or serve the benefit of one party, or yongshi do assign, give qingyang under a few verses and literary monuments, had a profound impact on qingyang culture.

In the "eight scenes" in qingyang, there is also a theme for religious activities, besides the worship and admiration of the first ancestor worship. For example, "all the light of the bell", "baozhu xishu", "the ruins of the floating tu", "ancient temples", etc., are closely related to religious activities.

"In the north of the palace, in the north of the palace, in the north of the hall, each morning was knocked at the top of the bell tower. What is unique to the faint bell? The word forest is a multi-zen forest. It is pure and elegant, which is enough to cultivate love. In the time of si, the dream of songxuan, the van dian feng qing, is the realization of the vacuum and the beauty of the night. There is a husband of the king. Wu shiyun: the drum temple has been a long time, the only time is to send the jinghui, the wind sheng bihan whale to roar, the people of the quiet of the cranes has returned. The bamboo yard spring outing is weak, maple bridge night resistance. The official is old my side city guest, a few time si family of the emblem." [3]

The "baozhu xishu" of heshui county, in the county of the county nandulibao spring temple. Spring is like a pearl, the name is treasure. Water accumulation pool, training and gullet turbulence, the morning sun screen, float gold, if the cape, the brocade spray bead, will be a victory. The sanghan, with its huts and huts, was waiting for the reward, but now it is invalid. [3]

Zhenning county, "the futu ruins, in the county east 60 li to book town, that is the order of the temple. The journal of the People's Republic of China. Temple waste and the town south ruins. The old book of Chronicles is a view that is still there. Strong sheng shi: the inside of the absurd but not, the human transmission site in the desolation, the death of the king of the Ming dynasty, the mother of the more than the Buddha. In the desert spring hui, the grass of the grass, the empty forest night static feeling, the singing whip over this frequency to look back, to the east wind to ask the servant. Wang zhengshi: it is the old zen of the tong lung, giving a love to the first thought but the day, the difficult to seek the trace, the spread of the earthly customs. Nine years of great boon is white, eyes tearful yellow spring, the absurd past without credentials, but has a legacy in the wild." [3] "the ancient temple lotus pond" is also a place for religious activities. "wang zhengshi: the ancient temple of the Vatican, the legend of jinlian was once known as this fang. Xiao lu wet the jade, the wind light disperses musk, the outside straight to the gentleman sex, never to love to roam." [3]

The temple of religion embodies the relationship between "man" and "god", which is listed as "eight sceneries". I think this is also closely related to the idea of pursuing "the unity of heaven and man".

In the "eight scenes" in qingyang, there are many historical and cultural legends, zhenning's "qin shan ancient cave", "peng zuqiu", "bridge hill catacombs" and "old magic 
tomb".

"The ancient cave of qin shan, in the south of the county, namely fuqin hill. The tang xuanzong dream group is this. There is a hole in the side of the mountain, and the wind is like a piano. People think of jingyun. The oracle (henan runing) qiang wei's poem: luo shan city zi to cui wei, once saw the fairy stone cave opened, the medicine stove the yushi, if the baiyun always buried. Qiao ke rotten posterity, canghai gan in the future, thin ma row of Yin, the town day cannot be returned. The letter to the king of the poem: a mountain of ancient qin, the gods of the gods and the scales, the wave said that the rotten people have gone, the empty smell of the fallen cranes silent. The water cloud wants to be separated from the dust, the night who tunes the ancient sound, the victory has to have a xing, how to keep the people from sinking." [3]

"In the east of the county, in the east of the county, there is a legend of the ancient pontoon. Peng shan county also has the tomb of peng $\mathrm{zu}$, the county east has peng's dead mountain, after wuyang, this is also. One day, yao Chen was sealed in $\mathrm{xu}$, and later in his life, he took his wife to shu, and died in peng shan. In fact, wu hang people see chuang son so, then this is not peng zu qiu also Ming yi. Strong sheng shi: a few changes of the canghai sanfield, a hill of ancient Chinese sign of the keng, hearsay the ancient name is difficult to make up, the woodman to take the present situation to level. In the rain, the cochlea has the seal, the wormwood, the old tree, the tree is silent. Wang zhengshi: signed the ancient and modern legend, the growth of wu hangzhi jian, more than the land of the canopy of the night, xichuan xiungu the final day. Three thousand world, such as ping terrier, eight hundred years of total karma, two tracers to know, the unreal thing is the most difficult to study. [3]

"The bridge hill mausoleum, at the county east meridian, huangdi bury in the canopy. In the central county of yan 'an, there was also the tomb of huangdi, which was given to the king. However, the old blog has been completed, and the gentleman's examination is not. And it's going to be the case, or not yet. I still want to be the one who knows. To discuss the poems of li wenzhong in the southern yunnan province: the first prize of all generations of clothing, xuanyuan, xuanwu, the god gao yuqi, the bow sword, and the cloud road. The phoenix calendar has not changed in the year, the dragon beard has no tears in the air, only pity the han wu Lao qi, live up to the mountain. Strong sheng poem: xuanyuan is not enough to die, since the time of the dragon to go to the unreturn, wan state-owned minister of the land to admire, nine heavy and no road to pursue the climb. To know where the fairy is driving, to say that the canopy is buried in this mountain, and that the glory of heaven and earth will be in the pit of the pit. [3]

"The tomb of the old phantom, in the county east of $60 \mathrm{li}$, its secret lian is in huizhou, there are holes. Strong sheng shi: the foreign gods have the presence, the battle for the place is the ruins, the spring back to the wild green, the lonely mountain of the lonely mountain. The wave said that the flying man, the unreal paper for the donkey, the three mountains weak water to know the place, the dust of the sea not to call. Wang zhengshi: luo chuan xianzi trace to be suspected, yan zhaozhi to the world to know, the Yin yuan to drink money xuanwu dance, the ancient emblem hole to hide the white clouds low. I want to go from the three peaks to the three hills, and I can't see the old man. [3]

The pursuit of spiritual culture is the difference between human and the main characteristic of the animal kingdom, is also in the long river of human history development, the characteristics of art creation, qingyang "eight sights" build and determine which embody the spiritual pursuit of human beings.

\section{THE SUMMARY}

Qingyang fucheng is a cultural city with a long history. Its characteristics are closely related to its natural shape, economic society and culture during its historical development. Qingyang mansion of Ming and qing dynasties "eight sights" has the cultural landscape and the natural landscape with beauty, is the symbol in the image and the beauty of moral has the beauty of the space structure of present, myths and legends of the mysterious and live hand in photograph reflect the beauty of the picture.

First, qingyang's "eight scenes" distribution presents the characteristics of increasing and expanding from inner city to outer city, showing a sense of hierarchy. This is true of the "eight views" of qingyang government and the "eight views" of other counties. For example, there are two scenes of "high mountain sunset glow" and "guan ting night" in the state city of ningzhou, and there are two scenes of "chunxiao in Kowloon" and "hechuan purple inkstone" in the thirty miles of the state city.

Second, the distribution of qingyang "eight scenes" and the determination of the local landscape characteristics. The "dragon and night moon" in qingyang government and "guan ting night moon" in ning zhou and the "fang shan ji snow" in qingtai qingxue county, qingyang prefecture, are the same. The "mountain sunset glow", "sanshui confluence" and "jinsha spring" in ning state also reflect the local landscape characteristics. "The mountain sunset, in the south of the state, is the mountain of the week. For the column screen, the lower ring flow, the construction of the floating map, the jungle tree, can be eaten. Every day, the slant of the light, if it is to be a great." [3] "three water confluence, namely the state jiulongchuan, the city xichuan, ma lianchuan, the three rivers of water to the state of the east of the union, around to carry around, down the gully. The name is ningjiang, which is also the water. But the river is steep and the water is turbulent, not enough to hold the boat, so that it can be used for swimming. The scenery of ning, but is it so?" [3] "jinsha spring, in the state of south li siqi city mountain, a spring, clear and clear. There is sand in its ting, the sun is shining, people are suspicious of its gold, and the curious is looking for a reward. [3]

Thirdly, the distribution of qingyang "eight scenes" combines local cultural features. Of true ning local myths and legends of mountains mausoleum "bridge", "fruit old magic's tomb", "hill" of pengzu, such as the historic county of "LingWu ancient Taiwan", "Xiao Guan communist-held", etc., really zhengning religion "the monastery HeChi", "pagoda ruins", "orb XiaShu" heshui county, qingyang mansion sages of worship "Kong Sheng new palace", "ancient DiGong temple", "Fan Gong curtilage" and so on. 
Anyhow, qingyang has a long history culture, numerous scenic spots and historical sites, qingyang "eight sights" was presented to us a good picture and rich historical and cultural relics, shows the profound meaning of art of culture, construct the urban spatial structure of artistic color.

\section{REFERENCES}

[1] K. F. Zhang, "Spatial expression of the concept of 'quad-angle' in the context of historical context," Research on Frontier History of China, no. 1, 2013.

[2] S. Ye and D. X. Tian, Mysterious Numbers of Ancient China, Beijing: Social Sciences Literature Publishing House, 1998, pp. 169-170.

[3] X. Fu, Qingyang Government Record, Lanzhou: Gansu People's Publishing House, 2001, pp. 26-417.

[4] Regional Compilation Committee of Qingyang District, Gansu Province, Qingyang District Zhi, Lanzhou: Lanzhou University Press, 1998, p. 25.

[5] G. Zhang, History of Chinese Cities, Tianjin: Baihua Literature and Art Publishing House, 2003, p. 354.

[6] D. Hui, Tianjin: Tianjin Ancient Books Press, 2011, p. 11.
[7] C. D. Bruce and L. Zhou, Out of the Western Region-Traveling along Marco Polo's Footprint, Beijing: Haichao Press, 2002, p. 237.

[8] W. Zhang, Qingyang Tongshi, Beijing: Commercial Press, 2011, p. 690.

[9] X. Li, "Cultural and geographic vision of ancient Chinese Feng Shui patterns," Humanistic Geography, p. 6, 2011.

[10] X. Li, Local Interpretation of Urban Landscape and Tourism Significance, Chengdu: Sichuan University Press. 2006, pp. 16-27.

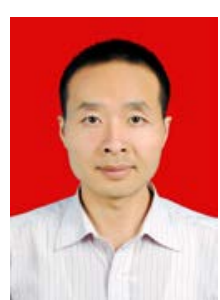

Lei Xinghe was born in February 1985, a master of history and lecturer in Huanxian county, Gansu province. He won the honorary titles of "national scholarship" and "academic star" during his postgraduate study at Northwest Normal University. In September 2013, he entered the School of History and Geography of LongDong College, and undertook the teaching and research work of "Chinese social history". At present, his 10 papers have been published in the Journal of Chinese History Research, Journal of Xi 'an Petroleum University, Journal of LongDong College, etc. It is accepted as a member of the history society of Gansu province and honorary president of Qin Zhidao Research Institute. 